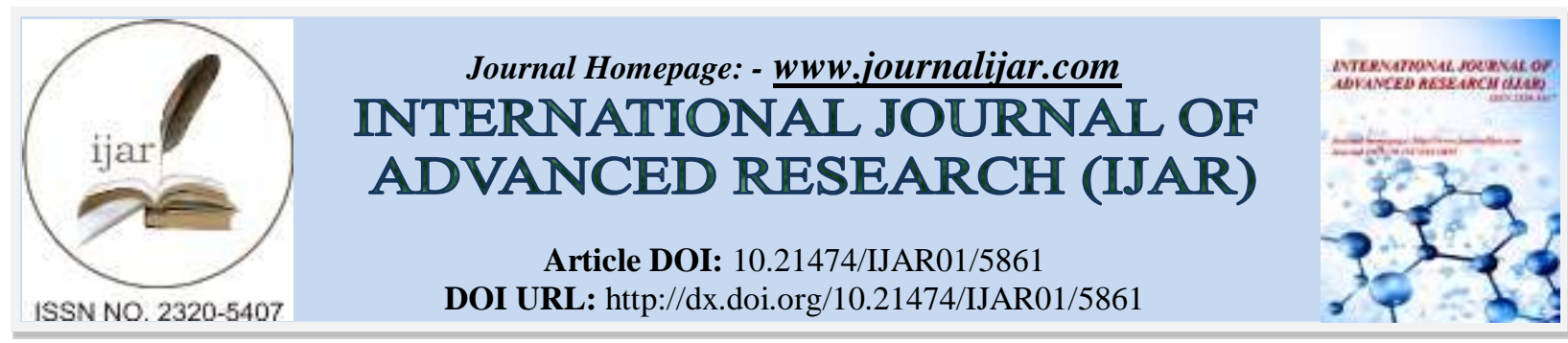

RESEARCH ARTICLE

\title{
IMPROVING THE EDUCATION OF THE DUMAGATS: DESIGNING AND DEVELOPING A SPECIALIZED CURRICULUM.
}

\author{
${ }^{*}$ Valdez Janet R. ${ }^{1}$, Galvez. Rosalyn ${ }^{2}$, Vistan Alejandro Saratan ${ }^{3}$, Dr. Claudio $\mathrm{Jr}^{4}$, Dayao. Ryan ${ }^{5}$ and Vivar \\ Elizabeth ${ }^{6}$. \\ 1. La Consolacion University Philippines Graduate School. \\ 2. La Consolacion University Philippines Student Affairs and Services. \\ 3. La Consolacion University Philippines Quality Assurance Office. \\ 4. Manila City Hall. \\ 5. La Consolacion University Philippines Basic Education Department. \\ 6. La Consolacion University Philippines Night College.
}

\section{Manuscript Info}

Manuscript History

Received: 14 September 2017

Final Accepted: 16 October 2017

Published: November 2017

Key words:-

Educational improvement, dumagat, specialized curriculum.

\section{Abstract}

The unquestionable relevance of education in the eradication of poverty and promotion of economic growth places education at the center of individual pursuits for social mobility. In consideration of the belief that education promotes societal and economic development of an individual, educators and policymakers should collaborate in the efforts of bringing education to the people, including its indigenous communities. Indigenous communities preserve their traditional education sans innovation, sans technology; thus, limiting their opportunities. In tribal education, knowledge is gained from first-hand experience and then transmitted or explored through ritual, ceremony, art, and appropriate technology. Tribal education, in this context, becomes education for "life's sake" ( Cajete, 2006).

This study aimed to improve the education of the Dumagats in Norzagaray, Bulacan by designing and developing a specialized curriculum. The research was constructed as a case study of the educational practices of the Dumagats of Norzagaray, Bulacan using the ethnographic techniques of observation, document collection, and recording of conversations and interviews. Data included the results of the interviews: unstructured and semi-structured covering content areas on literacy history and intergenerational practices, literacy acquisition and learning, literacy use in everyday life, adult education, employment needs, and literacy use in daily life.

Copy Right, IJAR, 2017,. All rights reserved.

\section{Introduction:-}

The unquestionable relevance of education in the eradication of poverty and the promotion of economic growth places education at the center of individual pursuits for social mobility. Education is the key towards social mobility in a highly stratified socio-economic society. One of the State Policies contained in the 1987 Philippine Constitution, Section 17 states that "The State shall give priority to education, science and technology, arts, culture, and sports to foster patriotism and nationalism, accelerate social progress, and promote total human liberation and 
development." Aside from this, education is considered a human right which allows improvement of one's standard of living.

In consideration of the belief that education promotes societal and economic development of an individual, finding ways to improve education is of paramount importance. Thus, educators and policy-makers should collaborate in the efforts of bringing education to serve more people. Mei Kuin (2009) asserted that "schools with primarily indigenous and ethnic minorities in low socioeconomic areas have long been associated with low levels of achievement, particularly in literacy."

With these in mind, the researchers proceeded to Norzagaray where an indigenous group of people called the Dumagats live. The Public Information Office (PIO) of the Municipality of Norzagaray described Norzagaray as covering a portion of the Sierra Madre Mountain Range situated at the southeastern end of Bulacan bordering the Municipality of Montalban in Rizal Province, on the north by the Municipality of Doña Remedios Trinidad, on the west by the municipalities of Angat and Santa Maria, and on the southwest by the City of San Jose del Monte. More than one-third of the land area of Norzagaray falls within Angat Watershed that was delineated through Proclamation 71 dated March 10, 1927 covering a total area of some 62,310 hectares of the Sierra Madre in the Provinces of Bulacan and Nueva Ecija. The journey led the researchers to the 'Punduhan ng mga Dumagats' which is a ten-hectare property serving as a focal point for cultural and trading activities for the Agta-Bulos, Aeta or Dumagats tribes who had maintained their cultural traditions and customs by continuously living in the remotest place in the mountains. The Dumagats were named after naked people of the forest who had been referred to as the Aeta communities inhabiting the place.

Therefore, the geographical location prohibiting accessibility poses a challenge in educating the Dumagats. Thus, indigenous communities preserve their traditional education sans innovation, sans technology limiting their opportunities. In tribal education, knowledge is gained from first-hand experience and then transmitted or explored through ritual, ceremony, art, and appropriate technology. Knowledge gained through these vehicles is then used in everyday living. Tribal education, in this context, becomes education for "life's sake" ( Cajete, 2006).

Moreover, by bringing education to the people, rather than people to education, they create the possibility for real personal, organizational and community learning on-the-ground in developing countries (Zuber-Skeritt \& Teare, 2013).

\section{Statement of the Problem:-}

This study aimed to improve the education of the Dumagats in Norzagaray, Bulacan by designing and developing a specialized curriculum.

Specifically, the study foud the answers to the following questions:

1. What is the current curriculum used by the Dumagats?

2. What kind of education do the Dumagats have?

3. How do the Dumagats get access to education?

4. What specialized curriculum should be designed and developed to improve the education of the Dumagats?

\section{Methodology:-}

The research was constructed as a case study of the educational practices of the Dumagats of Norzagaray, Bulacan using the ethnographic techniques of observation, document collection, and recording of conversations and interviews. Data included the results of the interviews: unstructured and semi-structured covering content areas on literacy history and intergenerational practices, literacy acquisition and learning, literacy use in everyday life, adult education, employment needs, and literacy use in everyday life. The procedures for data collection are as follows:

1. The researchers sought the help of the Municipality of Norzagaray who provided a guide to trudge the slopes of the Dumagats.

2. Data collection was done in a day where indigenous community members were sought for interviewing. The sampling was opportunistic, according to the availability of the interviewees. Key informants, including their volunteer trained teacher, were sought for interviewing.

3. Observations were made of community members engaging in everyday education practices and events. 


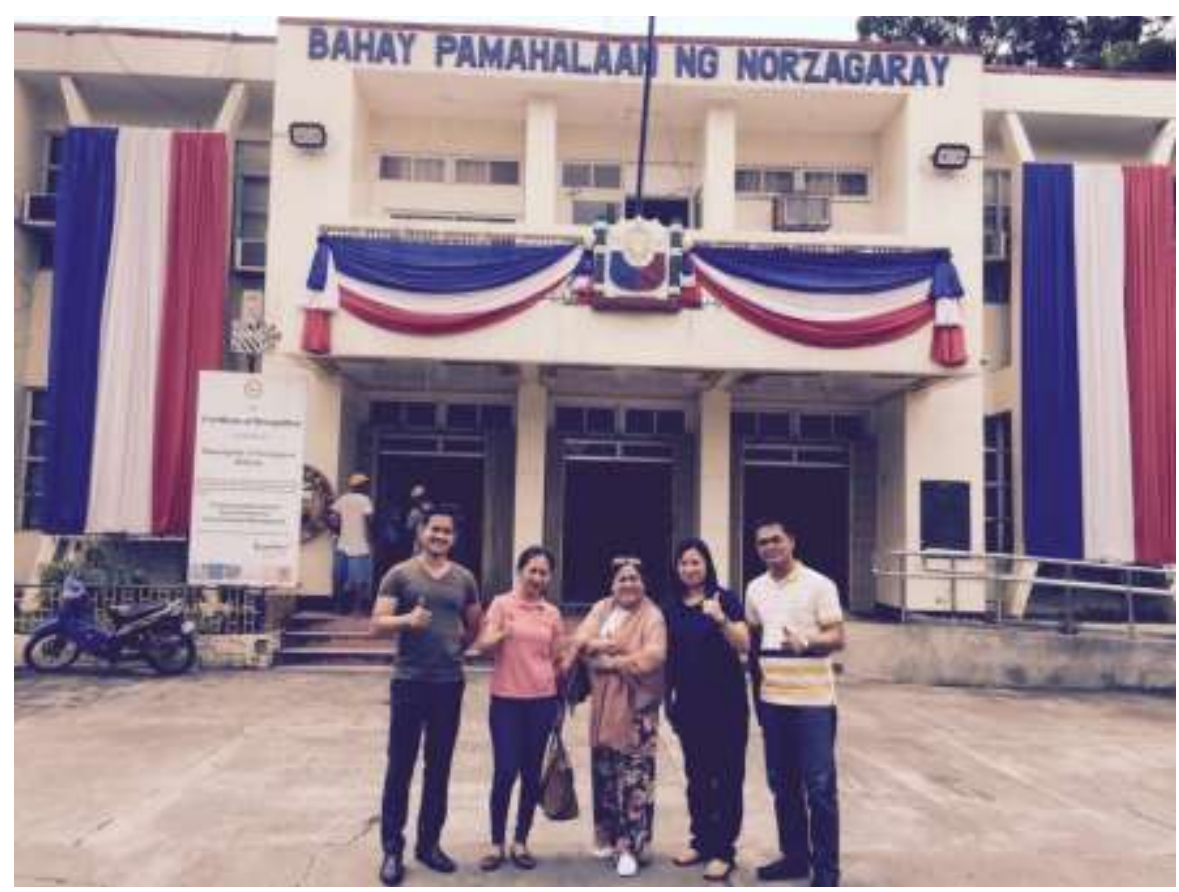

At the Municipality of Norzagaray and the Office of the Human Resources Head, where the researchers coordinated to seek permission to conduct the observation and interview and request a guide to bring them to the location of the Dumagats

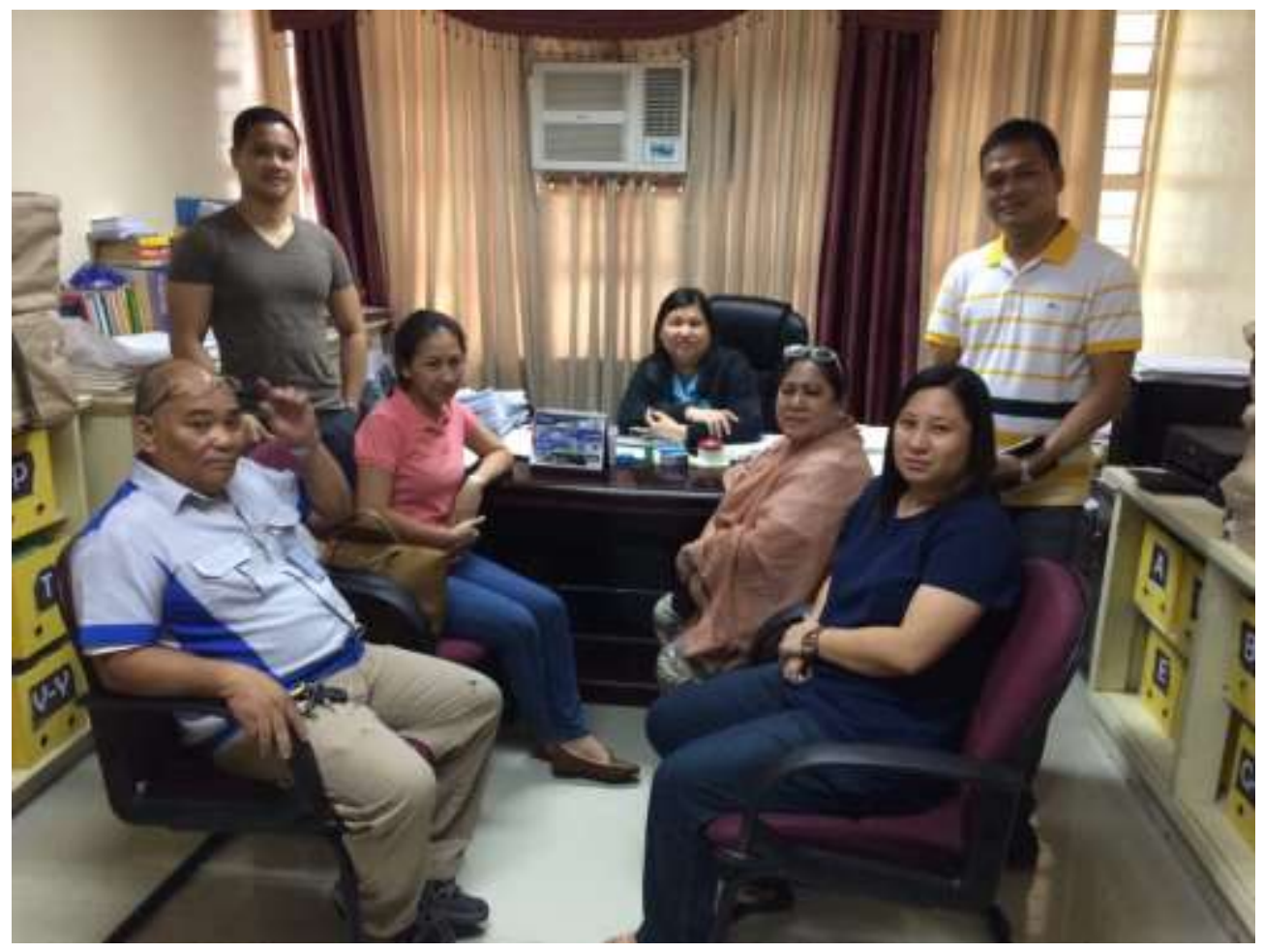




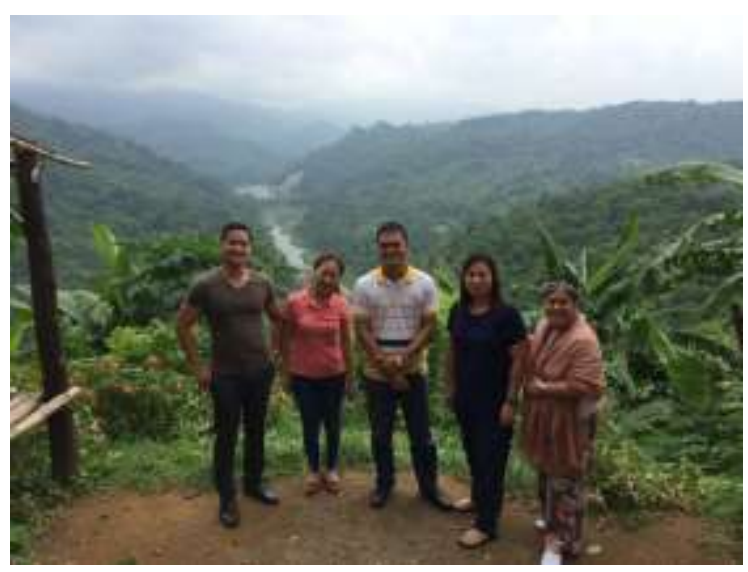

The researchers trudged through the terrains of the location of the Dumagats.

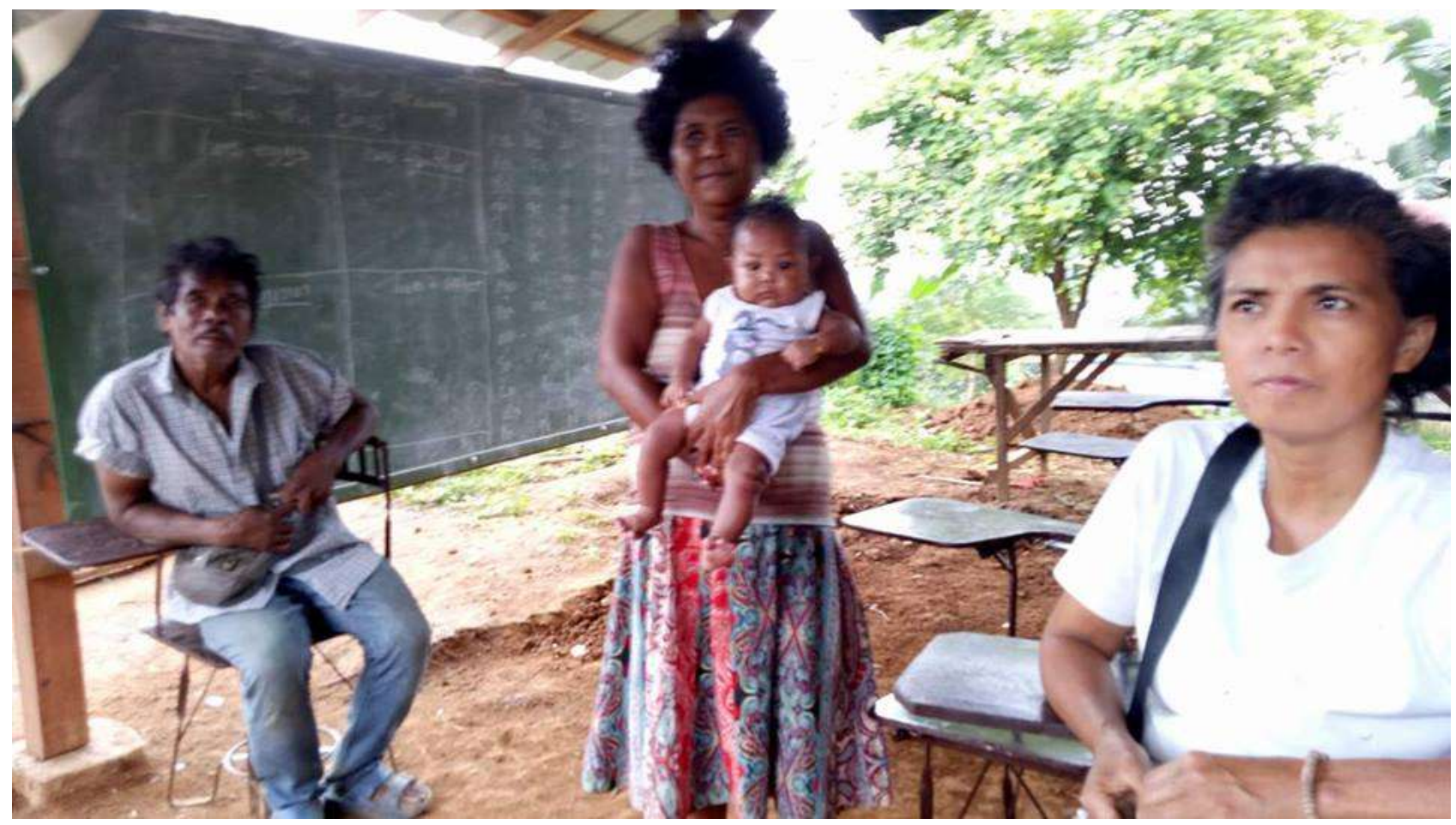

The volunteer trained teacher with other members of the Dumagat community. 

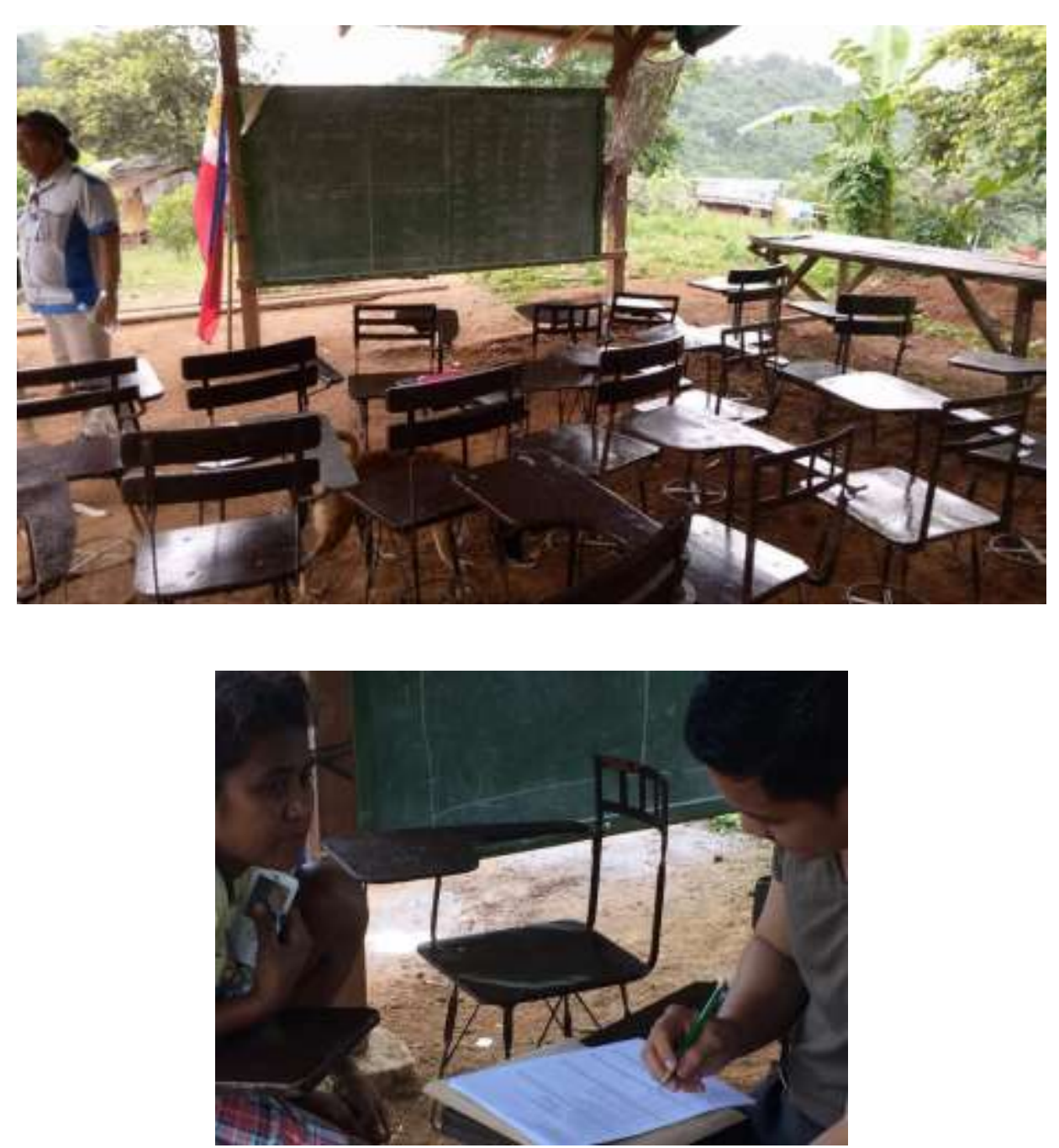

Data gathering

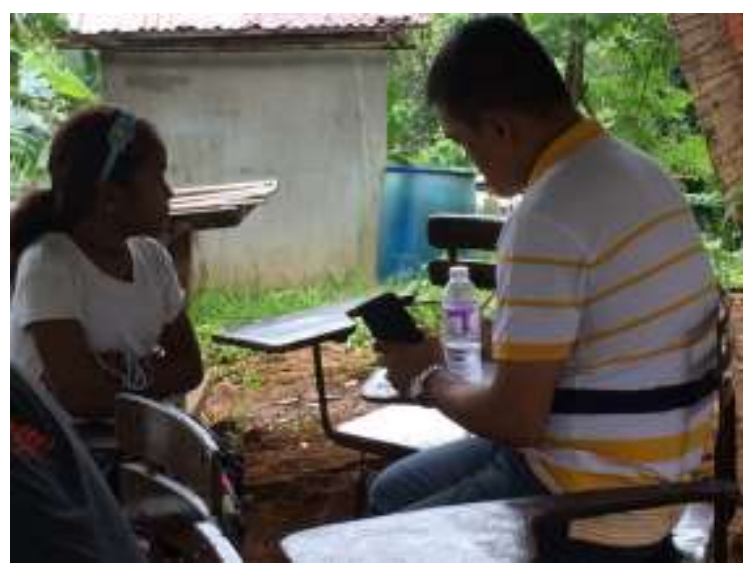




\section{Results and Discussions:-}

After the study, the researchers present the following findings:

\section{Problem 1:-}

The current curriculum used by the Dumagats:-

The Dumagats, aged ten years and above, are taught using a curriculum adhering to the provision of basic literacy that would allow the learners the skills and abilities to read and write in Filipino and English. There was no formal, written, and documented curriculum that guides the volunteer trained teacher. On the other hand, the ALS teacher teaches the Dumagats with an alternative specialized curriculum for basic reading and writing open to all Dumagats. The schedule is followed on a monthly basis; thus, follow up is done by the volunteer trained teacher alone.

\section{Problem 2:-}

The kind of education of the Dumagats:-

During the day of the observation, the green board which was, also, functioning as a wall on one side of the improvised classroom, contained visible phonetic lessons of syllables and three-letter English words hand-written in manuscript. It was a school day and time; yet, the classroom was devoid of students. When the bell was rung by the volunteer trained teacher, the members of the community gathered. The researchers found out that at the time of the interview, four (4) out of the fifty-six (56) or 7.14\% of the total respondents, ten years and above, can read and write.

\section{Problem 3:-}

The access to education of the Dumagats:-

The Dumagats receive their education in their communal habitat. Their education is delivered by a volunteer trained teacher, considered as their leader, who is one of them and an Alternative Learning System (ALS) teacher who comes to them every month. There is no school building nearby where the Dumagats can access free formal basic education. Their classroom lacks sufficient provisions for formal schooling. No books were in sight during the observation and interview. The uncemented rocky road from their location to the nearest school is a long walk, which by vehicle took us around thirty minutes, down the mountain.

\section{Problem 4:-} Specialized curriculum designed and developed to improve the education of the Dumagats:-

The researchers recommend a specialized curriculum through the Alternative Learning System (ALS) that combines literacy and functionality for the community. This would include the basic literacy necessary in learning to read and write in both Filipino and English. The focus of the curriculum is on agriculture since their community is, still, in the process of developing their communal habitat after being displaced by the Angat watershed rehabilitation programs. They know how to clear their lands and plant crops using their crude tools. Training them in the use of modern farm instruments and teaching them with better technological innovations in agriculture improve their education; therefore, their livelihood. Aside from agriculture, the curriculum should include fishing and fishing technology. There are abundant indigenous materials from the forest trees that can be used for cottage industries or other means of livelihood. Agriculture, fishing, cottage industries, and other skills for lifelong learning should be the primary content of the specialized curriculum for the Dumagats. Furthermore, the need to learn on protecting wildlife and the forest, as well as, their ancestral lands should be part of the curriculum.

\section{Conclusion and Recommendations:-}

In the light of the following findings, the following observations and recommendations are drawn:

1. The adult population of the indigenous community of the Dumagats in Norzagaray comprise a portion of the remaining 3.4\% percent of the Philippine population with the inability to read and write. These Dumagats maintain the aspiration to acquire the ability to read and write, especially their children who they dream of having a better life. However, the younger Dumagats are trilingual with the ability to speak three (3) dialects namely: Tagalog, bulos, and kabuluan. On the other hand, the adult Dumagats possess the ability to communicate in the dialect of their forefathers which is palumagat.

2. The inability of the Dumagats to develop literacy stems from the lack of access to free basic education due to their remote geographic location, being situated in the Sierra Madre Mountain Range. Evidently, the government lacks sufficient provision for the delivery of its service to the community. 
3. The priority of the Dumagats is daily subsistence, although they desire basic education, especially for their younger generation who the elder people encourage to find better life by being educated. Their daily education is accessed from their routine activities including clearing of their land, planting and harvesting crops, and fishing.

4. The government services, including access to free education, do not reach the Dumagats; thus, their daily routine differs from the other people in the lowlands in the town of Norzagaray. While the schooling children in the lowlands are at school, the schooling children in the Punduhan wait for instructions and time to be taught.

5. The Dumagats preserve their communal practices and traditions including their daily provisions of meals and activities. The families share one cooked meal and eat in the vicinity designated as the classroom.

6. Their communal life centers on agriculture; thus, seminars and trainings on agriculture and other livelihood using indigenous skills and materials within their vicinity can better equip them in their daily subsistence.

7. The specialized curriculum should focus on the provision of knowledge, skills, and technological know-how in agriculture, aquaculture, forestry, and other areas necessary in their daily subsistence.

\section{References:-}

1. Huang, S., \& Liu, S. (2016). Discrimination and incorporation of Taiwanese indigenous Austronesian peoples. Asian Ethnicity, 17(2), 294-312. doi:10.1080/14631369.2015.1112726

2. Kral and Falk (2004). What is all that learning for? Indigenous adult English literacy practices, training, community capacity and health. Commonwealth of Australia.

3. McKAY, T. (2017). BUILDING A COMMUNITY OF LIFELONG LEARNING. Phi Kappa Phi Forum, 97(2), 10-13

4. Mei Kuin, L., McNaughton, S., Amituanai-Toloa, M., Turner, R., \& Hsiao, S. (2009). Sustained Acceleration of Achievement in Reading Comprehension: The New Zealand Experience. Reading Research Quarterly, 44(1), 30-56.

5. Retrieved from Knoema World Data Atlas https://knoema.com/atlas/Philippines/topics/ Education/Literacy/Adult-literacy-rate on August 27, 2017. 